
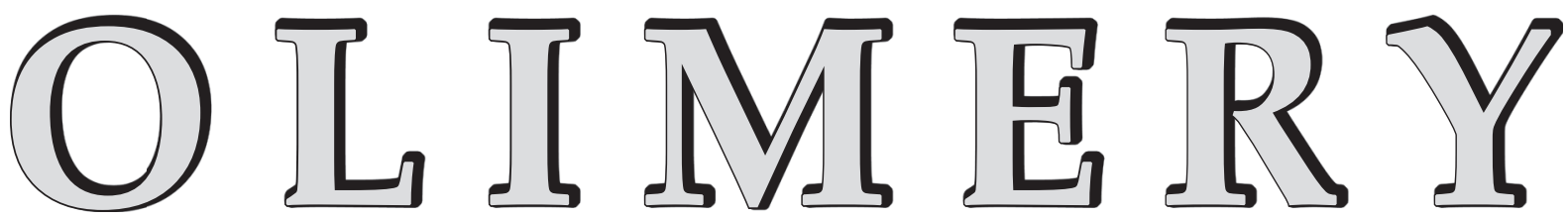

CZASOPISMO POŚWIĘCONE CHEMII, TECHNOLOGII i PRZETWÓRSTWU POLIMERÓW

\title{
All-polymer composites - a new approach with the use of disentangled semi-crystalline polymers*) Part II. Preparation of composites from partially disentangled polylactide
}

\author{
Justyna Krajenta1), Andrzej Pawlak ${ }^{1), * *)}$, Andrzej Galeski ${ }^{1)}$ \\ DOI: dx.doi.org/10.14314/polimery.2020.4.1
}

\begin{abstract}
The mechanical properties of two uniaxially stretched polylactides have been studied: the polylactide with reduced density of entanglements of macromolecules and with equilibrium density of entanglements. It has been shown that plastic deformation is easier in a partially disentangled polymer. Thus, this polymer was used to form an all-polymer composite by blending it with a second molten polymer: poly(butylene succinate) or polystyrene. During mixing, polylactide fibers were produced that strengthened the prepared composite.
\end{abstract}

Keywords: polylactide, polymer composites, mechanical properties, macromolecular entanglements.

\section{Kompozyty w pełni polimerowe - nowe podejście z użyciem rozplątanych częściowo krystalicznych polimerów \\ Cz. II. Otrzymywanie kompozytów zawierających częściowo rozplątany polilaktyd}

Streszczenie: Oceniano właściwości mechaniczne podczas jednoosiowego rozciągania dwóch rodzajów polilaktydu: ze zmniejszoną gęstością splątań makrocząsteczek i z równowagową gęstością splątań. Wykazano, że częściowo splątany polimer łatwiej ulega deformacji plastycznej. Z tego względu użyto go do wytworzenia kompozytu całkowicie polimerowego w wyniku zmieszania z drugim stopionym polimerem - poli(bursztynianem butylenu) lub polistyrenem. Podczas mieszania polimerów powstawały włókna polilaktydowe wzmacniające wytworzony kompozyt.

Słowa kluczowe: polilaktyd, kompozyty polimerowe, właściwości mechaniczne, splątania makrocząsteczek.

\footnotetext{
1) Polish Academy of Sciences, Centre of Molecular and Macromolecular Studies, Sienkiewicza 112, 90-363 Lodz, Poland.

*) The part of article was presented at the Pomerania-Plast 2019 Conference, June 5-7, 2019, Międzyzdroje, Poland.

**) Author for correspondence: apawlak@cbmm.lodz.pl
} 
Composites based solely on polymers, known as selfreinforced polymer composites or all-polymer composites, are still a small part of all those produced. This results, among others things, from problems in processing, the overcoming of which requires an additional effort in relation to conventional composites. However, the all-polymer composites have a number of advantages, which justifies the research dealing with the optimization of their production methods [1-3]. The advantages of all-polymer composites include their lower specific gravity, the ability to ensure good adhesion of components, and easier recycling (for example by melting). However, the process of their formation is usually more expensive and requires greater control. There are two main strategies for obtaining these composites: a) choosing one or two polymers to create a composite, b) selection of a single step or multistep production route [4]. The most common process for forming an all-polymer composite is to introduce commercially available polymer fibers [UHMWPE - ultra-high molecular weight polyethylene, PP - polypropylene, PET - poly(ethylene terephthalate), PA - polyamide] into a matrix of the same or different polymer. For some polymer pairs, it is possible to make composites directly in the melt blending process [4] with fiber formation during the mixing, or later due to the orientation of the material during the receiving phase. It is not the goal of this paper to discuss in detail the methods for obtaining this class of composites, especially as they have been well described in the literature [1-5].

A few years ago, Galeski with co-workers proposed a new method of producing nanocomposites $[6,7]$, based on the ability to achieve large plastic deformations by polymers with limited density of macromolecular entanglements. When partially disentangled polymer, being in the solid state, is mixed at a high temperature with a second, molten polymer, the forces acting on it induce the plastic deformation. During this deformation, the crystalline elements are fragmented, the amorphous phase is stretched and as a result fibrillar structures are formed. If the loose network of entanglements in the amorphous phase allows large deformations, the mixing process will end up creating nanofibers, dispersed in the molten polymer. After decreasing the temperature and solidifying the melt, a fully polymeric composite is formed in this way. The method was successfully used to produce nanocomposites based on partially disentangled polypropylene.

In the first part of this work, the preparation of partially disentangled polylactide (PLA) was described. The extent of disentanglement was confirmed by rheological tests and the crystallization of the partially disentangled polymer was discussed. In the second part of this paper, it will be shown that the partially disentangled polylactide has also modified mechanical properties, mainly visible during the plastic deformation phase, and is therefore suitable for the preparation of nanocomposites. The formation of composites in two different polymer matrices was described, and the mechanical properties of the obtained nanocomposites were shown.

\section{EXPERIMENTAL PART}

\section{Materials}

Poly(L-lactide) Nature Works NW 4032D was used in the research. The following values of molecular masses were determined using GPC-MALLS: $M_{n}=72000 \mathrm{~g} / \mathrm{mol}$, $M_{w}=88000 \mathrm{~g} / \mathrm{mol}$.

The poly(butylene succinate) (PBS) provided by Sigma-Aldrich is a biodegradable, aliphatic polyester with a melt flow index $M F I=10 \mathrm{~g} / 10 \mathrm{~min}$. The GP585X polystyrene (PS) from Synthos had a melt flow index of $8 \mathrm{~g} / 10 \mathrm{~min}$.

\section{Composites preparation}

Partially disentangled polylactide was obtained by dissolution in methylene chloride, rapid cooling in liquid nitrogen and precipitation with ethanol. Details of the procedure are described in the first part of this paper. For testing of the mechanical properties and attempts to make nanocomposites, polylactide obtained from a solution with concentration of $0.5 \mathrm{wt} \%$ was used. The choice of PLA $0.5 \mathrm{wt} \%$ instead of PLA $0.1 \mathrm{wt} \%$, which was studied in the first part of this paper as well, was associated with a small density of entanglements in the latter, which could be insufficient to ensure the transmission of forces during deformation and achieve large degrees of deformation. The properties of partially disentangled polymer, marked as PLA0.5, were compared with the properties of fully entangled polylactide, marked as PLAi.

Two polymers were selected for the matrices of composites: poly(butylene succinate) (PBS) and polystyrene (PS). By choosing such chemically different matrices, we wanted to check whether PLA composites can be made from very different sets of polymers. In addition, the nanocomposite of polylactide and poly(butylene succinate) would be an example of a composite made only of biodegradable components. For the second composite (PS/PLA), the matrix polystyrene can easily be removed by dissolving it in toluene, which allows microscopic analysis of the PLA fibers produced. Polylactide composites were made by mixing PLA0.5 with PBS at temperature of $115^{\circ} \mathrm{C}$ or with PS at a temperature of $147^{\circ} \mathrm{C}$. The temperatures were optimized so that the PLA was not melted and the second polymer was viscous enough to transmit the shear and tensile forces effectively. The PLA content was 5 wt \%. The mixing of polymers was carried out using the EHP-5CS mini extruder (Zamak, Kraków). The plasticizing system of this extruder is composed of two screws with a variable profile and a return channel with a valve, allowing the material to pass through the extruder multiple times. Mixing conditions for PBS/PLA were as follows: mixing time $10 \mathrm{~min}$, screw rotation speed $200 \mathrm{rpm}$, while for PS/PLA: 5 min of mixing at $150 \mathrm{rpm}$. At the end, the mixed polymers were collected from the machine to form a composite after solidification. The mixing process required the optimization of the temperature and mixing 
time, but when they were properly selected, as specified above, homogeneous materials were obtained.

\section{Methods of testing}

- The mechanical properties of disentangled and entangled polylactide were tested during uniaxial stretching using the Linkam TST 350 mini tensile machine. Due to the high glass transition temperature of PLA $\left(60-61^{\circ} \mathrm{C}\right)$, limiting the possibility of deformation before break to $5-15 \%$ of strain [8], the tests were carried out at $T=60^{\circ} \mathrm{C}$. Samples with working dimensions $3.8 \times 1.5 \times 0.2 \mathrm{~mm}$ were prepared by hot pressing in short time (2-3 $\mathrm{min})$. They were deformed at a rate of $10 \% / \mathrm{min}$. The deformation process was recorded by a video camera and due to this it was possible to determine the true stress-true strain or true stress-extension ratio dependencies and measure of the volume changes. The true strain $\varepsilon$ is defined here as $\varepsilon=\ln \left(l / l_{0}\right)$, extension ratio as $\lambda=\left(l / l_{0}\right)$, where $l$ is the actual length of the measured section of the sample, and $l_{0}$ is the initial length of the same section.

- The morphologies of the composites were analyzed using a Jeol scanning electron microscope, observing the surfaces prepared by breaking the samples in liquid nitrogen and sputtering using gold. In the case of the PS/PLA composite, a residue was also observed after removal of polystyrene by dissolution in toluene.

- The mechanical properties of the composites were studied during uniaxial stretching at an elevated temperature $\left(100-120^{\circ} \mathrm{C}\right)$. The Instron testing machine equipped with a temperature chamber was used. The deformation rate was $5 \% / \mathrm{min}$ for the PBS/PLA composite, the gauge dimensions of the samples were $12.5 \times 5 \times 0.5 \mathrm{~mm}$, whereas for the PS/PLA composite due to good deformability at $T=120^{\circ} \mathrm{C}$ a higher deformation rate was chosen, i.e. $10 \% / \mathrm{min}$.

- Additionally, for the PS and its PLA composite, an extensional viscosity fixture test was performed using the special attachment for the Ares rheometer. Samples in the form of $18 \times 10 \times 0.7 \mathrm{~mm}$ size films were heated to $T=135^{\circ} \mathrm{C}$ before starting the test, which was carried out at a straining rate of $0.1 \mathrm{~s}^{-1}$.

\section{RESULTS AND DISCUSSION}

\section{Mechanical properties of PLAs}

The mechanical properties of PLAi and PLA0.5 samples were tested by uniaxial stretching at $60^{\circ} \mathrm{C}$. During the deformation, local changes in length and width were recorded. Assuming that the changes in the thickness are proportional to changes in width, it was possible to determine not only the maximum local strains, but also the minimum cross-sections at a given moment of the experiment, thus determining the true stress. The dependences of true stress-extension ratio for PLAi and PLA0.5 are shown in Fig. 1.

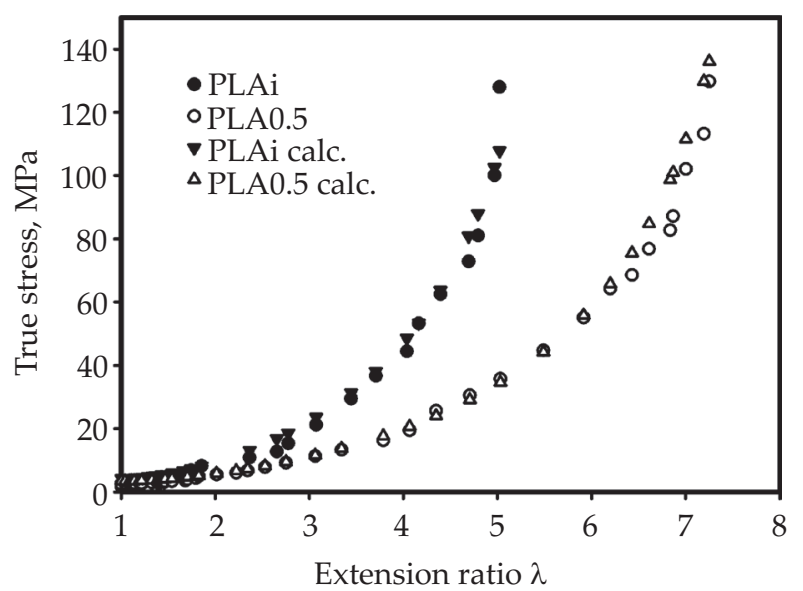

Fig. 1. Dependences of true stress-extension ratio for PLAi and PLA0.5 tested at $T=60^{\circ} \mathrm{C}$; in addition to the experimental data, the calculation results are also shown

Both compared materials exhibited plastic deformation with high strain to break. Stresses at the yield as controlled by the crystalline phase were similar in magnitude and were: 2.3 MPa for PLAi and 3.2 MPa for PLA0.5, with the same strain 0.03 . Small stress values resulted from a high temperature during the measurements. At high strains, starting from extension ratio $\lambda=1.5$, differences in the behavior of both polylactides appeared. In PLAi, stress began to increase due to the self-reinforcement process, while PLA0.5 comparatively easily deformed even at $\lambda=2.5$. Both materials achieved high stresses at $150 \mathrm{MPa}$ before breaking.

It is assumed that the course of the deformation for the large strains is controlled by a network of entangled macromolecules and therefore in more entangled PLAi stresses increase faster due to a greater resistance from the entanglement network. The tensile deformation of polymer assuming a rubber-like character of molecular network deformation may be described by the Eq. (1):

$$
\sigma=\sigma_{y}+\sigma_{R}\left(\lambda^{2}-1 / \lambda^{2}\right)
$$

where: $\sigma$ - the true stress, $\sigma_{y}$ - the yield stress, $\sigma_{R}-$ the strain hardening modulus, and $\lambda$ - the extension ratio. Unfortunately, it was impossible to describe the experimental data from Fig. 1 using this equation. Therefore, a more advanced Arruda-Boyce model was applied $[9,10]$. The strain hardening modulus in this model is described by Eq. (2):

$$
\sigma_{R}=\frac{N_{e} k T}{3}\left(\frac{3-x^{2}}{1-x^{2}}\right)
$$

where: $N_{e}$ - the effective crosslinks density, $k$ - the Boltzmann constant, and $T$ - the temperature. The $x$ variable is equal:

$$
x=\sqrt{\frac{\lambda^{2}+1+1 / \lambda^{2}}{3 n}}
$$


where: $n$ - the number of "rigid links" between entanglements providing limited extensibility of a chain.

It was attempted to describe stress-strain experimental relationships using Eq. (2) and Eq. (3) by adjusting the values of $N_{\mathrm{e}}$ and $n$. The experimental points and points calculated according to the Arruda-Boyce model are similar if the following values have been used:

$N_{e}=5.1 \cdot 10^{26} \mathrm{~m}^{-3}$ and $n=14$ for PLAi, and $N_{e}=2.4 \cdot 10^{26} \mathrm{~m}^{-3}$, $n=25$ for PLA0.5. A larger value of $N_{e}$ for PLAi confirms the results of rheological measurements of entanglement density in both materials. A smaller value of $n$ means in turn a more limited ability to deformation for the polymer chains in PLAi. It is worth noting that the determined values of $N_{e}$ and $n$ are close to those calculated by Bartczak and Kozanecki [10] for different polyethylenes, and the relationship between more and less entangled samples of the same polymer are similar.

Recording of local changes of the length and width of fragments of the tested sample during the experiment allowed us to evaluate the changes in the volume of material during the deformation, usually given as the volume strain $\Delta V=\left(V-V_{0}\right) / V_{0}$. Here $V$ is the current volume of the most deformed fragment of the sample, $V_{0}$ is the initial volume of this fragment. Figure 2 shows how the volume strain changes in PLAi and PLA0.5 as a function of the extension ratio.

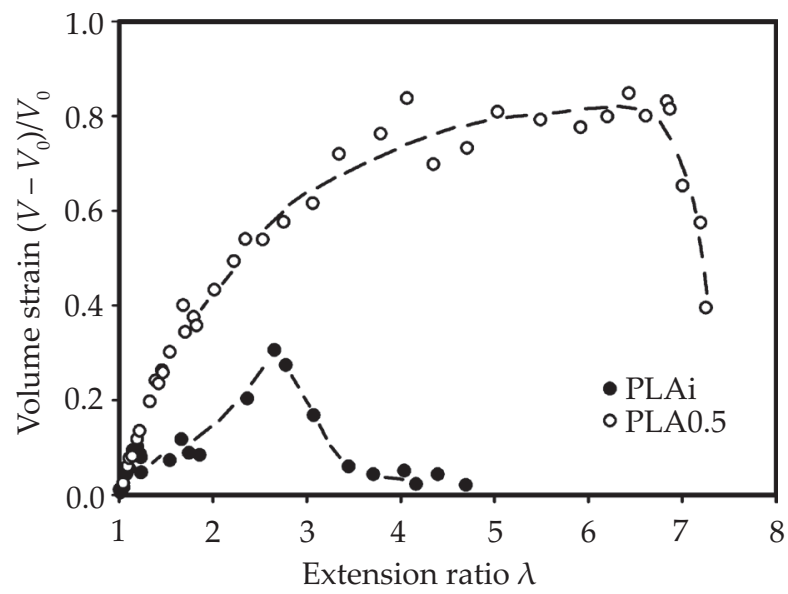

Fig 2. Volume strain in a function of the extension ratio for PLAi and PLA0.5; the lines are drawn to better display the results

In both materials, there was an increase in volume during deformation, visible from the yield point. In the case of PLAi, the increase was not larger than 0.3 and a similar growth of volume was previously observed in other polymers (e.g. polypropylene, polyethylene). It is usually explained by the reorganization of the crystalline structure. At high deformations, when the internal structure is strongly oriented, the volume strain gradually decreases. A much larger increase in volume occurred in the partially disentangled PLA0.5 and it reached the highest value equal to 0.85 at the extension ratio 5-6. The reason for such a large increase in volume is the formation of micro and nano size cavities, easier to initiate in the polymer with a limited density of entanglements. In the final stage of deformation, due to the large orientation of the surrounding polymer, these cavities gradually close, which leads to the limitation of volume strain.

Both samples whitened during stretching, but the PLA0.5 sample became opaque earlier. Whitening is another confirmation of the creation of micro cavities, which scatters the light. Comparing these observations with the volume strain measurements, it can be concluded that at large extensions a limited formation of cavities was observed in PLAi, whereas in PLA0.5 this process was very intense.

The studies characterizing partially disentangled PLA compared to fully entangled PLA showed significant differences in rheological behaviors (modules), the ability to faster crystallization with less defected crystals and modified mechanical properties. The better deformability in PLA0.5 indicated the possibility of using it to produce fibrillar fillers in an all-polymer composite. The formation of such composites is described in the next section.

\section{The formation of all-polymer composites}

The increased ability of the partially disentangled polylactide PLA0.5 to high deformation indicated that it is an interesting material for the preparation of a nanocomposite with a second polymer intended for a matrix. For the matrices of composites, we chose poly(butylene succinate) and polystyrene.

Figure 3 shows schematically what changes occur in partially disentangled PLA grains during mixing. The polymer initially contains crystals and an amorphous phase. During the mixing with the second polymer, tensile and shear forces coming from the mixer or extruder are transferred through the polymer melt to the PLA grains, which are still in the solid state. The grains are weakly bound, so they are fragmented, and at the same

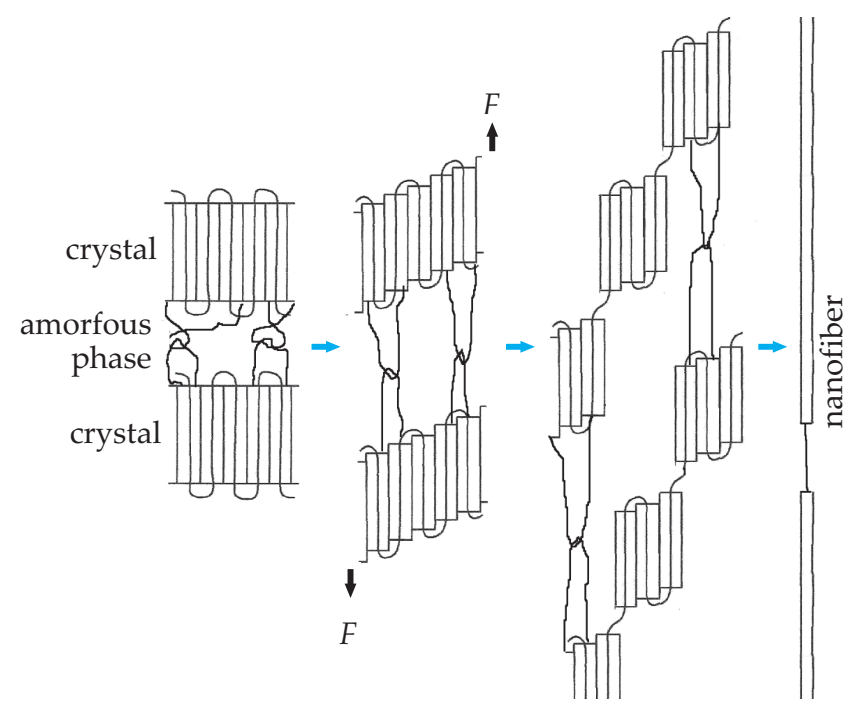

Fig. 3. The scheme of transformation of the crystalline-amorphous structure of PLA into nanofibers during mixing with the second molten polymer 
time the plastic deformation of the crystalline phase in them occurs. Because the deformation in partially disentangled PLA is less limited by the network of entanglements in the amorphous phase, it is possible to obtain a high degrees of deformation. The fragmented lamellar structure connected by the oriented amorphous phase is transformed into elongated fibrillar structure which, at the end of the mixing process, form thin fibers, mostly of nanometer diameters.

\section{Properties of PBS/PLA and PS/PLA composites}

After mixing, the morphology of the resulting materials was observed using a scanning electron microscope. Figure 4 shows the internal surface of the PBS/PLA composite containing $5 \mathrm{wt} \%$ of PLA. Microscopic observations confirm the formation of PLA fibers with a diameter below $100 \mathrm{~nm}$. The fibers are dispersed in the PBS matrix. They are often stretched and form a spatial network.

a)

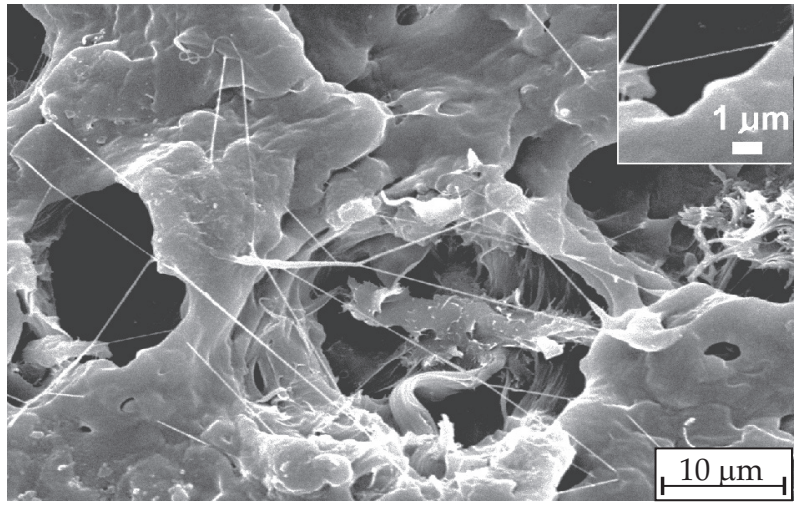

b)

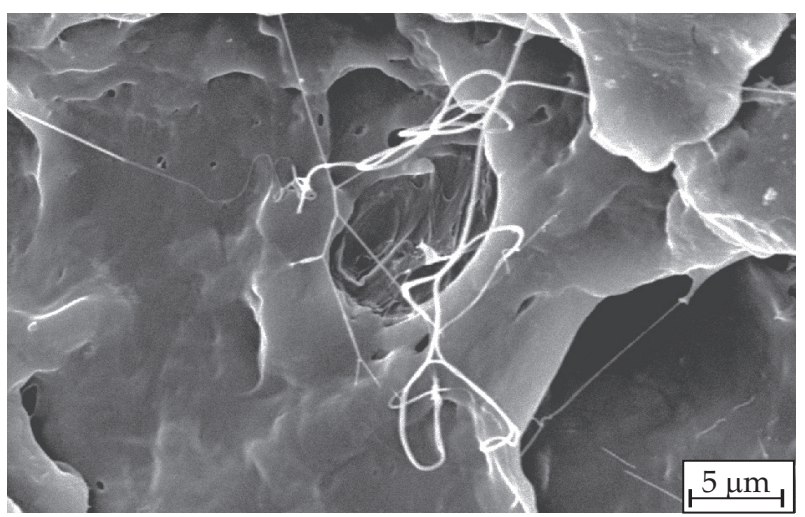

Fig. 4. Microscopic images of the PBS/PLA composite after breaking it in liquid nitrogen; insert show magnified fragment with visible $100 \mathrm{~nm}$ thick PLA fiber

Films were made of PBS/PLA and PBS, from which the samples were cut and their mechanical properties were tested in a tensile test. During measurements at room temperature and at $60^{\circ} \mathrm{C}$, the samples broke rapidly and it was difficult to find the effect of the presence of PLA fibers in the composite. It is possible that this was due to the poor adhesion between the filler and the matrix. Only after raising the temperature of the experiment to $100^{\circ} \mathrm{C}$, were the materials able to deform plastically and the differences in mechanical properties became more visible (Fig. 5).

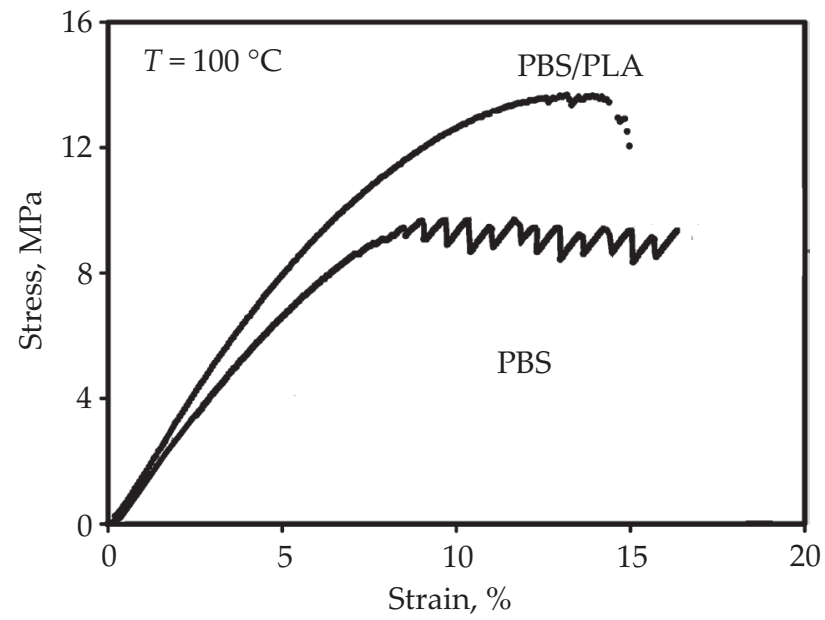

Fig 5. Mechanical properties of PBS and PBS/PLA composite during tensile deformation at $100^{\circ} \mathrm{C}$ at a rate of $5 \% / \mathrm{min}$

The studies of mechanical properties showed an increase in the elastic modulus of the composite by $28 \%$ in comparison with neat PBS, from 128 to $164 \mathrm{MPa}$, and an increase in yield strain from 9 to $15 \%$. The yield stress of the composite was $14.1 \mathrm{MPa}$, while in PBS it was only 9.7 MPa. Both materials exhibited similar elongation to break in the range of $14-17 \%$. Higher values of the Young modulus and stresses in the composite were obtained with a $5 \mathrm{wt} \%$ of PLA contents, although only $1 / 3$ of the reinforcing fibers were oriented in the direction of stretching. Therefore, the obtained effects should be considered significant. Stress fluctuations are visible for PBS for the strains larger than 9\%. They were observed earlier in some other polymers [11-13]. The reason of this effect is the accumulation of the heat of deformation in the sample, locally raising the temperature, facilitating further deformation with less stress and less heat generation. Then the temperature decreases locally, stress increases, more heat is released and the effect of stress oscillations is repeated. Oscillations are hardly visible to the composite, where the fibers might have allowed the heat to escape outside the deformation zone.

The second examined composite was made by the blending of PS with $5 \mathrm{wt} \%$ of PLA powder, at a temperature of $147^{\circ} \mathrm{C}$. After just 5 minutes of mixing, a homogeneous composite was obtained. Due to the nature of the matrix, it was possible to dissolve it and to visualize the resulting polylactide structures. As shown in the Fig. 6, the fibers were mainly formed from PLA, with a small content of spherical structures. The morphology of this composite resembles the morphology of previously examined composites with polypropylene fibers [7]. The PLA fibers have a diameter of $100 \mathrm{~nm}$ or less. The fibers are randomly distributed in space (although some local orientation may exists), and the places where they branch out are also visible. 


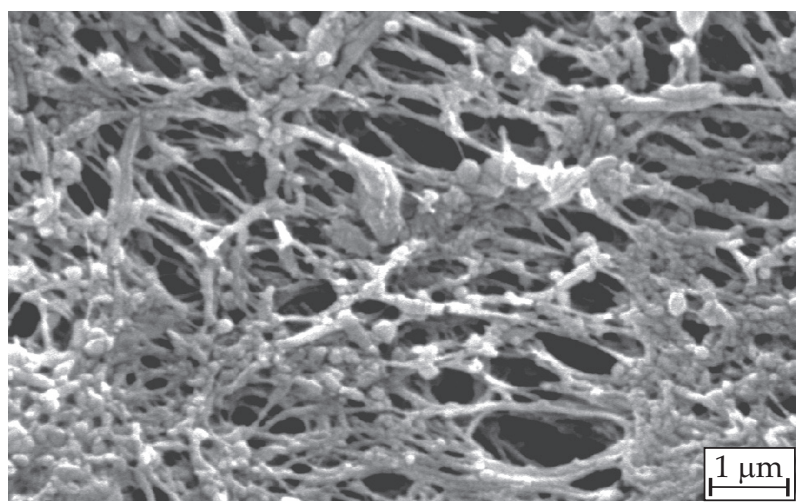

Fig. 6. The morphology of the PLA structures formed during mixing it with PS; the PS matrix was removed here by dissolution in toluene

We examined the mechanical properties of the PS/PLA composites during the tensile test. Due to the stiffness of the PS matrix below the glass transition temperature, i.e. $100^{\circ} \mathrm{C}$, and early breaking of the samples, the measurements were made at $120^{\circ} \mathrm{C}$. The representative stressstrain curves for the PS/PLA composite and PS alone are shown in Fig. 7.

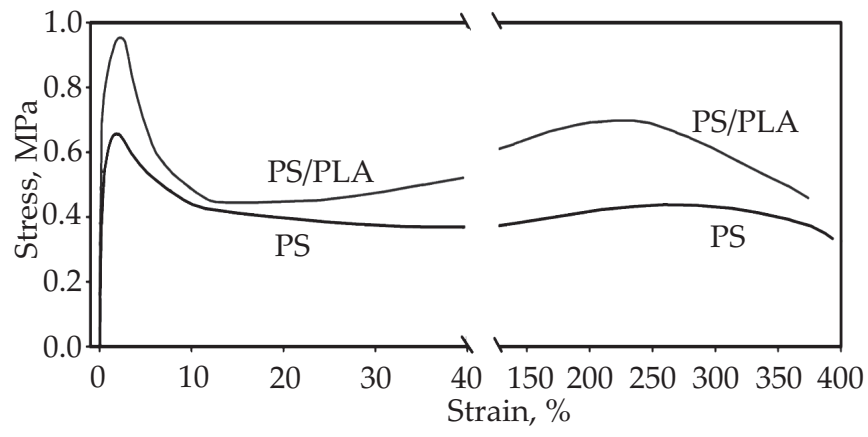

Fig 7. Mechanical properties of PS and PS/PLA composite during uniaxial stretching at $120^{\circ} \mathrm{C}$

The deformation proceeded with the formation of a neck, but the yield stress was much greater for the composite. Also in the strain-hardening phase the stress in the PS/PLA increased faster than in PS. Stress values were small due to the high temperature of the experiment. Both materials achieved large deformations of 350 $400 \%$. The stress during the hardening phase was even $50 \%$ higher in composite than in PS.

The second experiment performed with the PS/PLA composite was the extensional viscosity fixture (EVF). Its purpose was to assess what part of the stress is transmitted by the fiber network itself. The results of the experiment are shown in Fig. 8a, where it is seen how the recorded true stress changed during the deformation of the PS and PS/PLA samples.

Similar to uniaxial stretching, higher true stresses were observed for the composite. During this experiment the force was measured. The difference between the force measured for the composite and the force mea-

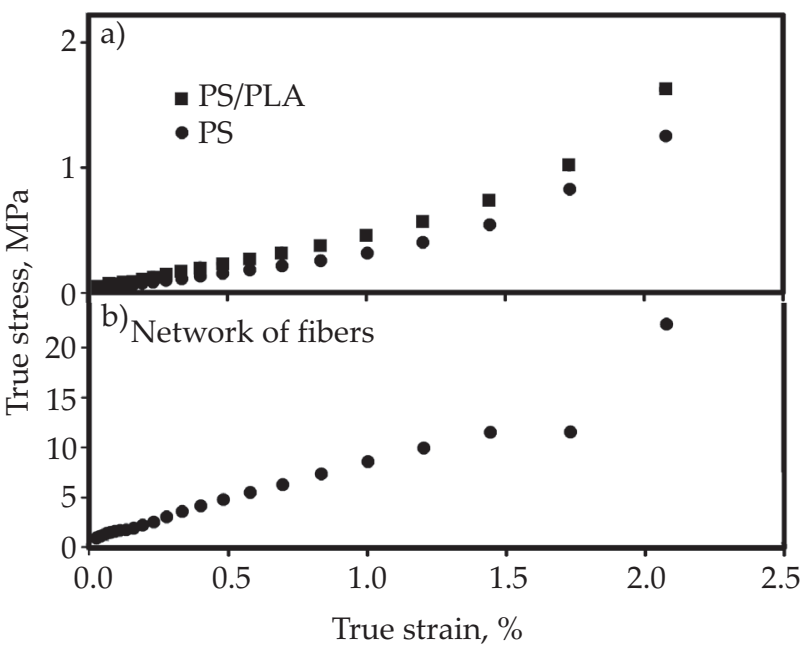

Fig. 8. Relationship between true stress and true strain for: a) PS and PS/PLA composite, b) network of PLA fibers, measured during the EVF rheological test at the temperature of $135^{\circ} \mathrm{C}$

sured for PS resulted from the contribution of PLA fibers. Knowing the content of fibers in the composite (5 wt \%) and taking into account that only $1 / 3$ of them acts in the direction of deformation, it was possible to estimate the total cross section of fibers on which the determined difference of forces acts. In this way, the stress component derived only from the PLA fiber network was calculated. The result is presented in Fig. $8 \mathrm{~b}$, where the net contribution of the PLA fibers to the composite strength is shown.

The stress value of the fiber network increased approximately linearly with the deformation up to the true strain of 1.5. For larger strains, the changes were less regular. The true strain reached a maximum value of $23 \mathrm{MPa}$ at the true strain of 2.1. This experiment showed a significant contribution of the PLA fibers to the transfer of stresses and thus to the mechanical properties of the composite. It should be remembered that these fibers do not form continuous structures over the entire length of the sample, but are connected with each other by mutual entanglements.

\section{CONCLUSIONS}

It has been shown that the three times reduction of macromolecular entanglements in polylactide significantly modifies its properties during stretching. In comparison to the fully entangled PLAi, the elongation at break increased significantly (from 5 to 7.5 of extension ratio). The stresses in PLA0.5 increased more slowly during plastic deformation phase, indicating the occurrence of some relaxation, including the creation of cavities. The occurring of the cavitation phenomenon was confirmed both by increase in the volume of the sample and by its whitening after exceeding the yield point.

The easier uniaxial deformation of partially disentangled polylactide indicated that it may be suitable for the preparation of polymer composites using the previously developed method [6]. This has been verified by blend- 
ing solid PLA0.5 powder with molten PS and PBS. The observations of morphology confirmed the presence of polylactide fibers in both matrices. The fibers have diameters of $100 \mathrm{~nm}$ or less. It has been shown in mechanical experiments that composites PBS/PLA and PS/PLA have better mechanical properties than pure PBS or PS matrices (although the improvement was observed mostly at elevated temperatures): larger modulus of elasticity and higher stresses at yield and at break. The elongation to break has also increased.

These results were achieved when the PLA fiber network in the polymer matrix was not oriented. It can be expected that in the case of polymer orientation forced during receiving the composite from the extruder, even better, though anisotropic, mechanical properties will be obtained.

The project was financed from the funds of the National Science Centre, Poland on the basis of the decision number UMO-2015/19/B/ST8/03870.

\section{REFERENCES}

[1] Gao C., Yu L., Liu H., Chen L.: Progress in Polymer Science 2012, 37, 767.

https://doi.org/10.1016/j.progpolymsci.2011.09.005

[2] Kmetty A., Barany T., Karger-Kocsis J.: Progress in Polymer Science 2010, 35, 1288.

https://doi.org/10.1016/j.progpolymsci.2010.07.002

[3] Karger-Kocsis J., Barany T.: Composites Science and Technology 2014, 92, 77. https://doi.org/10.1016/j.compscitech.2013.12.006

[4] Bhattaharyya D., Fakirov S.: "Synthetic Polymer Polymer Compsites", Hanser Verlag, Munich 2012.

[5] Bledzki A., Ries A., Passmann D.: Polimery 2011, 56, 369.

http://dx.doi.org/10.14314/polimery.2011.369

[6] Krajenta J., Pawlak A., Gałęski A.: Polimery 2015, 60, 10. http//dx.doi.org/10.14314/polimery.2015.664

[7] Krajenta J., Pawlak A., Galeski A.: Journal of Polymer Sciences. Part B: Polymer Physics 2016, 54, 1983. http://dx.doi.org/10.1002/polb.24105

[8] Galeski A., Piorkowska E., Pluta M. et al.: Polimery 2005, 50, 562. http://dx.doi.org/10.14314/polimery.2005.562

[9] Arruda E.M., Boyce M.C.: Journal of the Mechanics and Physics of Solids 1993, 41, 389. https://doi.org/10.1016/0022-5096(93)90013-6

[10] Bartczak Z., Kozanecki M.: Polymer 2005, 46, 8210. http//dx.doi.org/10.1016/j.polymer.2005.06.100

[11] Karger-Kocsis J., Benevolenski O.I., Moskala E.J.: Journal of Materials Science 2001, 36, 3365. http://dx.doi.org/10.1023/A:1017935323058

[12] Karger-Kocsis J., Czigany T., Moskala E.J.: Polymer Engineering \& Science 2004, 39, 1404. https://doi.org/10.002/pen.11531

[13] Pawlak A., Rozanski A., Galeski A.: Mechanics of Materials 2013, 67, 104. https://doi.org/10.1016/j.mechmat.2013.07.016

Received 3 IX 2019. 